\title{
Factors Influencing the Extent of Germination of Bacillus coagulans Spore Populations
}

\author{
By A. D. HITCHINS* \\ Unilever Research Laboratory, Colworth House, Sharnbrook, Bedford
}

(Accepted for publication 2 July 1968)

SUMMARY

The rate of germination of populations of spores of Bacillus coagulans decreased as germination progressed, late-germinating spores exhibiting a delay or decreased probability of germination. Delayed germination was not due to changes occurring in the environment during germination. Colonies formed by delayed individuals had a similar morphology to those produced by the rest of the population. Delayed individuals constituted not more than $5 \%$ of the total spore population. In a sample containing 17 delayed individuals, I4 gave spore populations with initial germination rates like that of the parent population, while three yielded populations which germinated at much slower rates. Delayed germination still occurred in spore populations grown from single colonies of the parent population. It was concluded that the spore populations were heterogeneous with regard to germination; reasons for the heterogeneity are discussed.

\section{INTRODUCTION}

Heterogeneity of spore populations has been noted or suspected in the phenomena of germination (Schmidt, I955; Hyatt \& Levinson, 196r ; Foerster \& Foster, 1966; Wax, Freese \& Cashel, 1967), heat activation (Busta \& Ordal, 1964) and ethylene oxide resistance (Church, Halvorson, Ramsey \& Hartman, 1956). The non-logarithmic curve of extinction-decrease of spore suspensions during germination (McCormick, 1964, 1965) was interpreted as being due to the heterogeneity of the spores (Vary \& McCormick, I965; Vary \& Halvorson, 1965). Further evidence for germination heterogeneity is presented here.

When a bacterial spore population in a constant germination environment exhibits a logarithmic decline in spore numbers due to germination it can be concluded that each spore has an equal chance of germinating, regardless of length of exposure to the germinant. However, when spore populations germinate, even under approaching constant conditions, some spores may still be detected long after most of the spores have germinated. When such ungerminated spores appear with greater frequency than expected from a logarithmic decline in spore numbers, they may justifiably be called delayed germinators. This paper reports experiments confirming the existence of delayed germinators and assesses the relative importance of environment and intrinsic factors.

\footnotetext{
* Present address: Department of Microbiology and Public Health, Michigan State University, East Lansing, Michigan, 48823, U.S.A.
} 


\section{METHODS}

Organisms and spore production. The organism used was Bacillus coagulans NCTC 399I, B. cereus $\mathrm{T}$ was also briefly examined. The parent population of $B$. coagulans spores had been stored at $4^{\circ}$ for 2 years in distilled water. It was produced as described previously (Hitchins, Gould \& Hurst, 1963).

Spore populations were derived from delayed germinators as follows. Spores of the parent population were incubated for 10 days in $10 \mathrm{mM}-\mathrm{L}-$ alanine + sodium metabisulphite $\left(\mathrm{Na}_{2} \mathrm{~S}_{2} \mathrm{O}_{5}\right)$ in sodium phosphate buffer $\left(\mathrm{pH}_{7} \cdot 0,100 \mathrm{mM}\right)$. Solutions of $\mathrm{Na}_{2} \mathrm{~S}_{2} \mathrm{O}_{5}$, sterilized by filtration, were added to germination media ( $0.16 \%$ final concentration) to prevent growth of germinated spores; this did not prevent initiation of germination (Gould, 1964). Use of $\mathrm{Na}_{2} \mathrm{~S}_{2} \mathrm{O}_{5}$ enabled the course of germination to be monitored for long periods of time. A sample was heated at $70^{\circ}$ for 30 min. to kill germinated spores and was found to contain about $0.01 \%$ of the original spore concentration. Single colonies derived from these residual spores were obtained by growth on yeast glucose agar. The colonies were subcultivated in nutrient broth aerated by agitation until free spores were again formed. Control spore populations were derived in the same way, but the germination and heating steps were omitted. Bacillus cereus $\mathrm{T}$ spores were produced in nutrient broth. All spores were grown at $37^{\circ}$. Viability of spores was determined by microscopic observation of a yeast glucose agar slide culture after incubation for $6 \mathrm{hr}$ at $37^{\circ}$.

Media and chemicals. Germination was done in yeast glucose broth (YGB) and

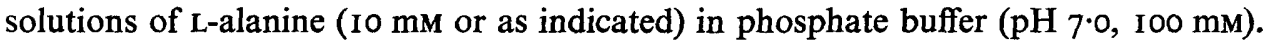
Bacillus cereus spores were germinated in solutions of L-alanine (IO $\mathrm{mM}$ ) or inosine (IO mM) in buffer. $O$-carbamyl-D-serine (OCDS) was the gift of P. H. Hidy (Commercial Solvents Corp., Terre Haute, Ind., U.S.A.). It was used at $\mathbf{2 . 4} \mathrm{mM}$ in germination media. Nutrient agar and sometimes yeast glucose agar were used for colony counts.

Germination. Spores were activated by heating to $70^{\circ}$ for $30 \mathrm{~min}$., unless otherwise stated. Throughout this paper the term germination refers solely to the initiation stage of germination during which heat resistance is lost. The germination temperature was always $37^{\circ}$ and the initial spore concentration was about $10^{6} \mathrm{spores} / \mathrm{ml}$., except as indicated. Germination kinetics were studied by counting the number of colonyforming units which survived heating at $70^{\circ}$ for $15 \mathrm{~min}$. or sometimes $10 \mathrm{~min}$. Samples were decimally diluted in sterile distilled water and pour-plates of appropriate dilutions prepared in duplicate. The plates were incubated at $37^{\circ}$ for 2 days. Longer incubations did not give significantly increased counts. The extent of germination was measured by counting the number of heat-resistant colony-forming units remaining in ro $\mathrm{mM}$ L-alanine $+\mathrm{Na}_{2} \mathrm{~S}_{2} \mathrm{O}_{5}$ in sodium phosphate buffer ( $\mathrm{pH} 7.0$, $100 \mathrm{~mm}$ ) after $17 \mathrm{hr}$.

Preparation of delayed germinators. Spores were added to warmed YGB containing $\mathrm{Na}_{2} \mathrm{~S}_{2} \mathrm{O}_{5}$ to a final concentration of about $3 \times 10^{6}$ spores $/ \mathrm{ml}$. The course of germination was followed by viable-spore colony counts. After $3 \mathrm{hr}$ the spore suspension was washed twice with cold sterile distilled water and heated at $70^{\circ}$ for $15 \mathrm{~min}$. to kill germinated spores. The resulting suspension was tested for rate of germination in fresh YGB without further heating.

Time course for appearance of delayed germinators. The course of sporulation in shake flasks of nutrient broth was followed by viable-spore colony counts. Samples ( $10 \mathrm{ml}$.) were heated ( $70^{\circ}$ for $30 \mathrm{~min}$.) to kill vegetative forms and the suspensions 
washed four times by centrifugation in cold sterile distilled water. The samples, containing spores still in sporangia, were tested for extent of germination. The inoculum concentrations were not more than $5 \times 10^{6}$ spores $/ \mathrm{ml}$. and were generally about $10^{6} / \mathrm{ml}$.

\section{RESULTS}

Viability

Spores (350) from the parent Bacillus coagulans population were examined by slide culture; all were found to be viable. Viable counts of the parent population were unaffected by heating at $70^{\circ}$ up to $2 \mathrm{hr}$ or by the nature of the plating medium.

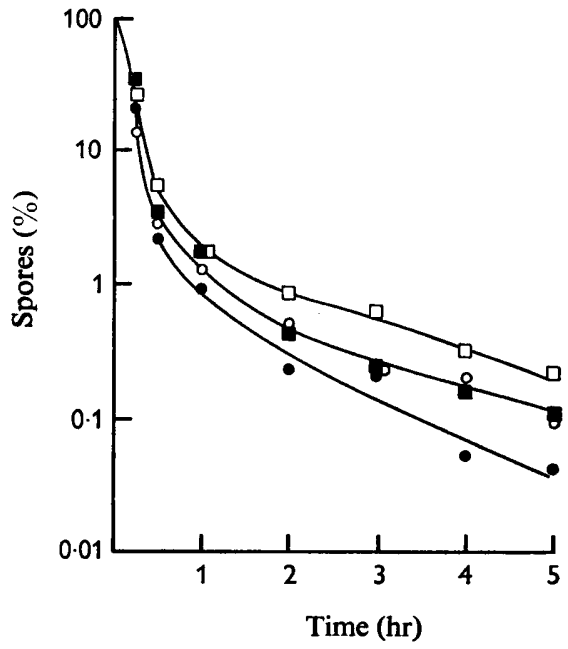

Fig. I

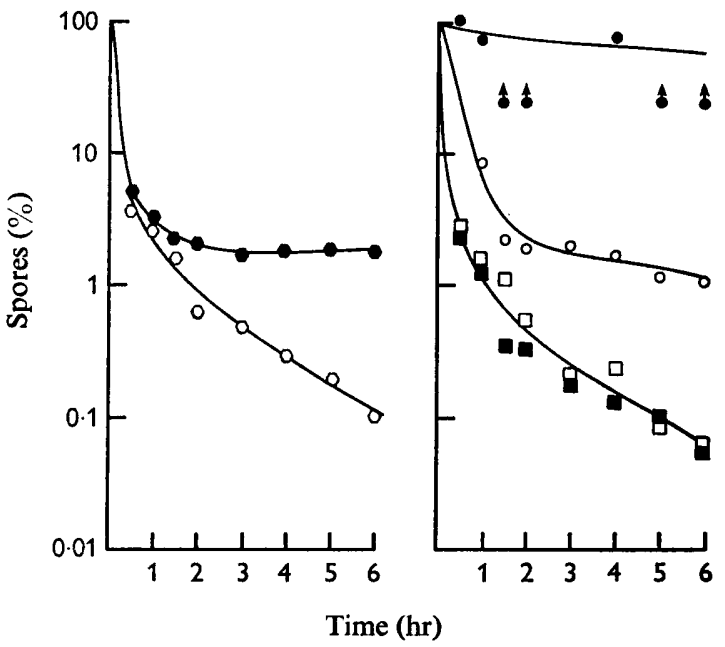

Fig. 2

Fig. I. Germination of Bacillus coagulans spores in YGB as affected by preheating and $\mathrm{Na}_{2} \mathrm{~S}_{2} \mathrm{O}_{5}$. $\mathrm{O}$, preheat only; $\square, \mathrm{Na}_{2} \mathrm{~S}_{2} \mathrm{O}_{5}$ only;, , control: no preheat, no $\mathrm{Na}_{2} \mathrm{~S}_{2} \mathrm{O}_{5}$; $\square$, preheat $+\mathrm{Na}_{2} \mathrm{~S}_{2} \mathrm{O}_{5}$.

Fig. 2. Effect of $O$-carbamyl-D-serine (OCDS) and spore concentration on Bacillus coagulans spore germination in $\mathrm{YGB}+\mathrm{Na}_{2} \mathrm{~S}_{2} \mathrm{O}_{5}$. Closed symbols, no addition; open symbols, with OCDS. Initial spore concentrations: $0,0,3 \times 10^{8} / \mathrm{ml}$; $, 0,3 \times 10^{7} / \mathrm{ml}$; $\mathrm{m}, \square, 3 \times 10^{6} /$ $\mathrm{ml}$. Samples held at $70^{\circ}$ for $10 \mathrm{~min}$. to kill germinated spores. Spores were not preheated. Symbols with arrows represent minimum estimates.

\section{Germination kinetics}

Figure I shows that the germination kinetics of Bacillus coagulans spores were nonlogarithmic and that there was an initial phase during which the majority of the population germinated rapidly, followed by a later phase of slow germination involving less than $5 \%$ of the initial population. The spores that germinated during the later phase thus showed a delay of germination as compared with the majority of spores in the population. Preheating and $\mathrm{Na}_{2} \mathrm{~S}_{2} \mathrm{O}_{5}$, although slightly inhibitory to germination, did not alter the typical non-linear shape of the germination curve. Since preheating generally stimulates the rate of spore germination the inhibitory effect was unusual, but was not investigated. Colonial morphology did not vary with sampling time during germination. Heat-shocked $B$. cereus $\mathrm{T}$ spores also germinated in a nonlogarithmic fashion in L-alanine, inosine or YGB. 


\section{Auto-inhibition of germination}

Figure 2 shows that germination was slower and less complete at high initial spore concentrations than at low ones. Also Fig. 2 shows that this auto-inhibitory effect was counteracted by the alanine racemase inhibitor OCDS (Lynch \& Neuhaus, 1966). OCDS stimulates germination by inhibiting spore alanine racemase (Gould, 1966), which catalyses production of the germination inhibitor D-alanine from L-alanine. The lack of effect of OCDS at the lowest spore concentration indicated that there was no auto-inhibitory effect due to $D$-alanine; however, delayed germination still occurred. The auto-inhibitory effect is shown further in Fig. 3, in which the \% delayed germinators is plotted against the total spore population. Above $10^{6} \mathrm{spores} / \mathrm{ml}$. the extent of germination decreased with increasing concentration, whilst below $10^{6} / \mathrm{ml}$. the extent of germination was independent of inoculum concentration.

\section{Effect of replacing the medium on the germination kinetics}

Two decimal dilutions of a germinating suspension at 10 and $20 \mathrm{~min}$. with fresh warmed medium did not alter the typical non-logarithmic shape of the curve. Initial spore concentration was only $2.5 \times 10^{6} / \mathrm{ml}$. and the final concentration of spores + germinated spores after dilutions was only $2.5 \times 10^{4} / \mathrm{ml}$. Environmental changes induced by the germinating spores such as those causing auto-inhibition should have been negligible. Furthermore, any inhibitors of germination produced should have been diluted by the fresh medium and counteracted by the high L-alanine concentration $(23 \cdot 2 \mathrm{~mm})$. Nevertheless, delayed germination was still apparent.

Delayed germinators obtained from a germinated spore suspension and representing about $0.2 \%$ of the initial population exhibited a logarithmic rate of germination that resulted in about $70 \%$ germination in $6 \mathrm{hr}$. Since the delayed germinators germinated slowly in fresh medium, the delay did not seem to be due to environmental changes occurring during germination.

\section{Effect of concentration of medium constituents and preheating on the extent of germination}

When the L-alanine concentration was kept constant (Io mM) the size of the ungerminated fraction increased from 0.02 to $0.30 \%$ with increase of the total molarity of the defined medium constituents from 0.07 to $0.50 \mathrm{M}$. At a buffer concentration of I00 $\mathrm{mM}$, increasing the $\mathrm{L}$-alanine concentration in the range $0 . \mathrm{I}$ to $\mathrm{IO} \mathrm{mM}$ decreased the ungerminated fraction from $\mathrm{r} \cdot 0$ to $0.02 \%$. The ungerminated fraction increased to $\mathrm{I} \cdot 0 \%$ when the L-alanine concentration was further increased to $200 \mathrm{mM}$, presumably because of the high molarity of the medium.

Preheating of spores did not alter the general shape of the germination curve (Fig. I). The extent of germination was not affected by preheating at temperatures below $80^{\circ}$ but at about $88^{\circ}$ preheating decreased the extent of germination (Table I). The apparent killing of spores at the highest temperature was confirmed in another experiment. During preheating at $83^{\circ}$ for $80 \mathrm{~min}$. there was a slight decrease in the extent of germination during the first $\mathrm{I} 5 \mathrm{~min}$. similar in size to that which occurred at $8 \mathrm{I}^{\circ}$ for $30 \mathrm{~min}$. (Table I), but after that there was no further change. The increased fraction of ungerminated spores observed after extreme preheating was probably due to a 
slower rate of germination caused by heat injury (Busta, 1967). It was concluded that preheating below $80^{\circ}$ does not cause delayed germination.

\section{Time of appearance of delayed germinators during sporulation}

Experiment $\mathrm{r}$ in Fig. 4 shows that the extent of germination was always incomplete and that delayed germinators formed a constant proportion no matter at what time the samples were taken during sporulation. Experiment 2 confirmed this result but differed in that the extent of germination was markedly less than in Expt. I. This was possibly related to a lower rate of aeration, since the rate of appearance of heatresistant spores was slower and the spore yield was lower than in Expt. I. Furthermore, considerable lysis of vegetative forms occurred during sporulation in Expt. 2. The results suggested that appearance of delayed germinators was not a function of the stage of sporulation.

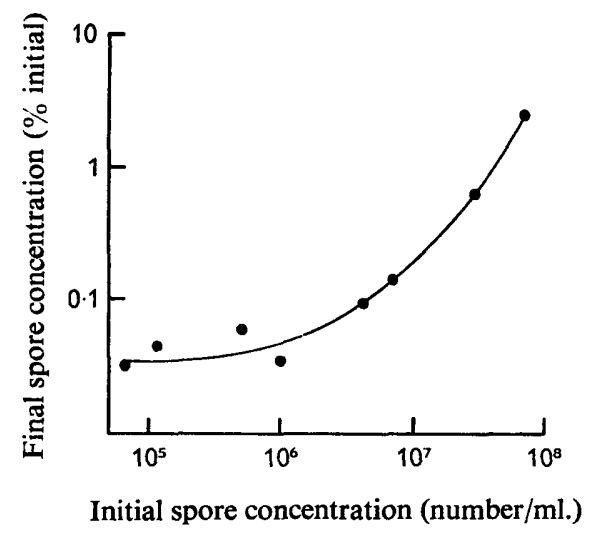

Fig. 3

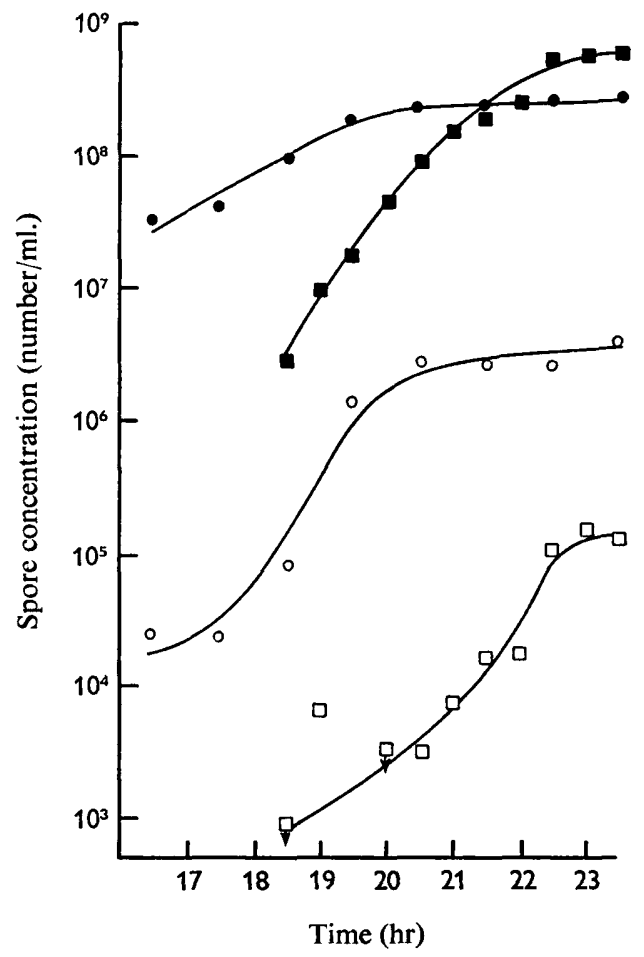

Fig. 4

Fig. 3. Bacillus coagulans. Relationship between the initial spore concentration and the size of the ungerminated spore fraction.

Fig. 4. Bacillus coagulans. Appearance of heat-resistant spores during sporulation. Closed symbols: total spore population. Open symbols: delayed germinators. Experiments: I, $\square, \square ; 2,0,0$. Symbols with arrows represent maximum estimates since the plates had less than ro colonies.

\section{Effect of subculture on the presence of delayed germinators}

Table 2 shows that delayed germinators yielded spore populations which germinated in most cases as quickly as unselected populations. Only three out of 17 delayed 
germinators yielded populations with very slow rates of germination. An unselected spore population derived from a colony of the parent stock and a fast-germinating population derived from a delayed germinator were found to have germination curves similar in shape to that of the parent population.

Table I. Effect of preheating on the extent of germination of spores of Bacillus coagulans NCTC 399I

$\begin{array}{cccc}\text { Temp. }\left({ }^{\circ}\right)^{*} & \text { Time (min.) } & \begin{array}{c}\text { Piability after } \\ \text { preheating }(\%) \dagger\end{array} & \begin{array}{c}\text { Ungerminated } \\ \text { spores }(\%) \ddagger\end{array} \\ 4 & - & 100 & 0.047 \\ 70 & 30 & 100 & 0.033 \\ 75 & 30 & 100 & 0.040 \\ 81 & 30 & 100 & 0.074 \\ 88 & 15 & 100 & 1.41 \\ 88 & 30 & 30 & 7.97\end{array}$

* Temperatures above $80^{\circ}$ were nominal values due to fluctuations.

$\dagger$ Based on an initial viable spore concentration of $1 \cdot 23 \times 10^{6} / \mathrm{ml}$.

$\ddagger$ Based on the concentration of viable preheated spores.

Table 2. Bacillus coagulans NCTC 399I. Germination times of spore strains derived from the parent suspension and its $0.01 \%$ ungerminated spore fraction

Germination time (min.)*

Less than 3

3 to 5

6 to 10

I I to 20

21 to 30

31 to 60

6 I to 76

Greater than 76

Number of strains tested

$\overbrace{\begin{array}{c}\text { From parent } \\ \text { population }\end{array}}^{\% \text { of strains }} \underbrace{\%}_{\begin{array}{c}\text { From } 0.01 \% \\ \text { fraction }\end{array}}$

$\begin{array}{rr}0 & 0 \\ 8 & 12 \\ 69 & 53 \\ 23 & 12 \\ 0 & 6 \\ 0 & 0 \\ 0 & 17 \\ 0 & 0 \\ 13 & 17\end{array}$

* Time taken for the extinction to decrease to $75 \%$ of its initial value, that for the parent suspension being $7 \mathrm{~min}$.

\section{DISCUSSION}

Since delayed germination was not eliminated by attempts to maintain a constant germination environment it can be concluded that it was due to the nature of the delayed germinators. If germination rate can be regarded as a measure of the degree of dormancy, then, although all the spores in the population were dormant, some were more dormant than others. The remarks in this paper only apply to spores that germinated and formed colonies within $48 \mathrm{hr}$. Spores exhibiting even greater degrees of dormancy would have remained undetected. However, the high viability of the stock spore suspension suggests that such spores, if present, were rare. Since germination heterogeneity was apparent in both simple germinant solutions and in yeast glucose broth, it seems that it was not due to a qualitative difference of germination requirements between fast and slow germinators. 
The only detectable factor that altered the constancy of the germination environment in this study was the auto-inhibitory effect of high spore concentrations (Fig. 2) which has. been described previously (Stedman, Kravitz, Anmuth \& Harding, I956; Stedman, Kravitz, Harding \& King, 1957). Auto-inhibition of germination is due to D-alanine being produced from the germinant L-alanine (Fey, Gould \& Hitchins, I964) by alanine racemase. D-Alanine is a well-known inhibitor of spore germination and it acts by inhibiting L-alanine-induced germination (O'Connor \& Halvorson, 196I). O-carbamyl-D-serine (OCDS) inhibits alanine racemase (Lynch \& Neuhaus, 1966) and its stimulating effect on germination is due to its inhibition of spore alanine racemase (Gould, 1966). Since the auto-inhibitory effect with $B$. coagulans was counteracted by OCDS it was probably due to the action of spore alanine racemase.

Woese, Vary \& Halvorson (1968) suggested that the non-logarithmic germination curve might be due to a Poisson distribution of a germination enzyme, which might be L-alanine dehydrogenase (Halvorson, Vary \& Steinberg, 1966) or perhaps the protein initiator of germination isolated by Vary \& Halvorson (1968). This would mean that the distribution of germination heterogeneity in the population is continuous. However, the results presented here could be interpreted as meaning that the germination heterogeneity is discontinuous, the population consisting of a mixture of two variants, the minority variant forming the delayed germination spore fraction. Unfortunately it is difficult to decide between the possibilities of a dichotomously or continuously variable population (Gilbert et al. 1964).

With Bacillus cereus spores delayed germination was apparent in the presence of the two germinants L-alanine and inosine. L-Alanine dehydrogenase is almost certainly not involved in inosine germination. This suggests that the variation of some spore component other than L-alanine dehydrogenase, but having a common relationship to the mechanisms of germinative action of both germinants, was responsible for the germination heterogeneity. Whatever the nature of the variable spore component, it was not affected by environmental conditions during spore formation by $B$ : coagulans. The fast- and slow-germinating spores both developed heat resistance at about the same time during sporulation, the slow ones not appearing markedly earlier or later than the fast ones.

Some of the delayed germinators may have been slow-germination mutants since they formed slow-germinating spore populations, but the majority formed fastgerminating spore populations. This may mean that if delayed germination was due to mutation, there might have been a high rate of reversion. At least some of the fastgerminating populations obtained from either fast or slow germinators were heterogeneous, since they also contained some delayed germinators, suggesting that the ability to produced heterogeneous populations is inheritable. Germination heterogeneity resembles in this respect the dissociation phenomena characteristic of the genus Bacillus (Braun, 1947; Smith, Gordon \& Clark, 1952; Moore, 1965) or the quantitative mode of inheritance of oligosporogeny (Northrop \& Slepecky, 1967). Alternatively, the apparent inheritability of heterogeneity is not inconsistent with a non-genetic explanation such as that of Woese et al. 1968. The relative importance of the various possibilities remains to be decided.

I am grateful to Dr G. W. Gould and Dr W. A. Hamilton for helpful criticism during the preparation of this paper. 


\section{REFERENCES}

BRAUN, W. (1947). Bacterial dissociation. Bact. Rev. II, 75.

Busta, F. F. (1967). Depression of germination in heat-injured Bacillus subtilis spores. Bact Proc. p. I. Busta, F. F. \& ORDAL, Z. J. (1964). Heat activation kinetics of endospores of Bacillus subtilis. J. Fd Sci. 29, 345.

Church, B. D., Halvorson, H. O., Ramsey, D. S. \& Hartman, R. S. (1956). Population heterogeneity in the resistance of aerobic spores to ethylene oxide. J. Bact. 72, 242.

FeY, G., Gould, G. W. \& Hitchins, A. D. (1964). Identification of D-alanine as the auto-inhibitor of germination of Bacillus globigii spores. J. gen. Microbiol. 35, 229.

FoERSTER, H. F. \& Foster, J. W. (I966). Response of Bacillus spores to combinations of germinative compounds. J. Bact. 9I, I 68.

Gilbert, G. L., Gambill, V. M., Spiner, D. R., Hoffman, R. K. \& Phillips, C. R. (ig64). Effect of moisture on ethylene oxide sterilisation. Appl. Microbiol. 12, 496.

Gould, G. W. (1964). Effect of food preservatives on the growth of bacteria from spores. In Microbial Inhibitors in Food. Ed. by N. Molin, p. 17. Uppsala: Almqvist and Wiksell.

Gould, G. W. (I966). Stimulation of L-alanine-induced germination of Bacillus cereus spores by $D$-cycloserine and $O$-carbamyl-D-serine. J. Bact. 92, 1261 .

Halvorson, H. O., Vary, J. C. \& Steinberg, W. (I966). Developmental changes during the formation and breaking of the dormant state in bacteria. A. Rev. Microbiol. 20, 169.

Hitchins, A. D., Gould, G. W. \& Hurst, A. (1963). The swelling of bacterial spores during germination and outgrowth. J. gen. Microbiol. 30, 445.

HyATT, M. T. \& Levinson, H. S. (I96I). Interaction of heat, glucose, L-alanine, and potassium nitrate in spore germination of Bacillus megaterium. J. Bact. 81, 204.

LYNCH, J. L. \& NeUHaUS, F. C. (1966). On the mechanism of action of the antibiotic $O$-carbamylD-serine in Streptococcus faecalis. J. Bact. 9I, 449.

MCCormick, N. G. (1964). The time-course of spore germination. Biochem. biophys. Res. Commun. 14, 443.

MCCORMICK, N. G. (1965). Kinetics of spore germination. J. Bact. 89, 1180.

Moore, W. B. (1965). Separation, characteristics and minimal amino-acid requirements of six variants derived from a strain of Bacillus cereus. J. gen. Microbiol. 40, 329.

NoRTHROP, J. \& SLEPECKY, R. A. (1967). Sporulation mutations induced by heat in Bacillus subtilis. Science, N.Y. I55, 838 .

O'ConNor, R. J. \& Halvorson, H. O. (196I). L-Alanine dehydrogenase: a mechanism controlling the specificity of amino acid-induced germination of Bacillus cereus spores. J. Bact. 82, 706.

SCHMIDT, C. F. (1955). The resistance of bacterial spores with reference to spore germination and its inhibition. A. Rev. Microbiol. 9, 387.

Smith, N. R., Gordon, R. E. \& Clark, F. E. (1952). U.S. Dep. Agric. Monograph no. 16, Washington, D.C.

Stedman, R. L., Kravitz, E., Anmuth, M. \& Harding, J. (1956). Autoinhibition of bacterial endospore germination. Science, N.Y. $124,403$.

Stedman, R. L., Kravitz, E., Harding, J. \& KING, J. D. (I957). Further studies on bacterial endospore germination relative to auto-inhibition. Fd Res. 22, 396.

VARY, J. C. \& Halvorson, H. O. (1965). Kinetics of germination of Bacillus spores. J. Bact. 89, I340.

VARY, J. C. \& HALVORSON, H. O. (I968). Initiation of bacterial spore germination. J. Bact. $95,1327$.

VARY, J. C. \& MCCORMICK, N. G. (I965). Kinetics of germination of aerobic Bacillus spores. In Spores III. Ed. by L. L. Campbell and H. Orin Halvorson, p. 213. Ann Arbor: American Society for Microbiology.

Wax, R., Freese, E. \& Cashel, M. (1967). Separation of two functional roles of L-alanine in the initiation of Bacillus subtilis spore germination. J. Bact. 94, 522.

Woese, C. R., VARY, J. C. \& Halvorson, H. O. (I968). A kinetic model for bacterial spore germination. Proc. natn. Acad. Sci. U.S.A. 59, 869. 